\title{
LOURENÇO FILHO E A NACIONALIZAÇC̃O DO ENSINO PRIMÁRIO (1917-1945)
}

\author{
WOJCIECH ANDRZEJ KULESZA \\ Universidade Federal da Paraíba (UFPB), João Pessoa, Paraíba, Brasil
}

\begin{abstract}
Resumo: Nascido em 1897, numa pequenina cidade do interior do estado de São Paulo, Manoel Bergström Lourenço Filho compartilharia com os brasileiros de sua idade as tensões, angústias e alegrias de ser filho de uma nação em busca de sua identidade no início do século XX. Neste trabalho procura-se reconstruir sua trajetória profissional, pontuando-se nos seus momentos mais significativos a relação entre seus conceitos de nação, estado e educação e as propostas efetivamente assumidas no âmbito do Ministério da Educação e Saúde. Essa análise permite perceber distintamente o uso que o intelectual Lourenço Filho faz de sua competência técnica para tentar impor suas concepções educacionais na definição das políticas para o ensino primário e normal durante o período considerado.

PalavRas-Chave: Intelectuais. Escola nova. Política educacional. Ensino primário.
\end{abstract}

INTRODUÇÃO

O período da história do Brasil inaugurado com a imposição pela força de Getúlio Vargas na presidência em 1930 foi palco de intensos debates acerca do futuro da nação. Ao contrário dos tempos da Primeira República, abria-se 
então a possibilidade efetiva de fazer valer na prática as propostas políticas para o país até então circunscritas à retórica dos gabinetes parlamentares ou acadêmicos. Para muitos, como pode ser aquilatado pelo extensivo uso na historiografia da denominação "Revolução de 30" para esse momento histórico, abria-se no país um tempo de mudanças que exigia uma transformação das instituições responsáveis pela nação brasileira. Assim, as demandas práticas colocadas desde o início ao governo provisório fizeram com que fossem implantadas políticas públicas de caráter nacional que vinham sendo insistentemente apregoadas, mas eram invariavelmente descartadas no período republicano anterior.

Com o movimento iniciado em 1930, os chamados intelectuais "optaram pela ocupação de cargos de direção do Estado para implementar a sua agenda de reformas sociais" (VIEIRA, 2015, p. 9), atuando num contexto no qual, desde os anos de 1920, estava se consolidando um novo campo cultural no país, não mais restrito às faculdades profissionais e às academias de ciências, letras e artes, mas que procurava contemplar a criação e o desenvolvimento das competências demandadas pela burocracia no poder. Como estas invariavelmente tinham como pré-requisito fundamental o domínio da escrita, a cultura letrada conheceu um enorme desenvolvimento, disseminando-se em todas as regiões e entre todas as classes sociais. No campo estritamente educacional, os autodenominados "profissionais da educação" ligados ao movimento escolanovista exemplificam paradigmaticamente essa nova condição social do intelectual no Brasil pós-1930.

A imediata criação de um Ministério de Educação e Saúde, significativamente subsumindo a saúde - único setor público no qual o governo central havia até então efetivamente experimentado uma política de intervenção nos estados através das campanhas do Departamento Nacional de Saúde Pública - reflete objetivamente o movimento pelo qual a concentração de poder no executivo se consolida através da centralização administrativa. Ao avocar ao Estado nacional a responsabilidade por uma política educacional com vigência em todo território nacional, cabia ao governo definir o sentido dessa atribuição para os estados e municípios, tradicionalmente encarregados do ensino primário. Todavia, como se sabe, as primeiras ações do novo Ministério 
recaíram sobre o ensino superior e sobre o ensino secundário propedêutico ao superior, níveis de ensino controlados pelo poder central desde a época do Império e alvos imediatos das reivindicações do "tenentismo" urbano e industrial no poder.

Exatamente um século depois do Ato Adicional de 1834, ao se retomar na constituinte de 1934 a questão de uma escola única para todos, investe-se o Estado nacional do dever de prover uma escolarização básica para os brasileiros ${ }^{1}$. Tendo recebido como herança do Império a descentralização da escola elementar, a República brasileira marcou passo durante 40 anos até que assumisse efetivamente a meta da escolarização básica para todos. Entretanto, em estreita associação com o avanço da modernidade, sob a influência das inovações pedagógicas em curso tanto na Europa como nos Estados Unidos, as elites intelectuais locais criticam duramente a educação tradicional, apropriando-se das diversas propostas metodológicas então em circulação, genericamente apresentadas sob a denominação de "escola nova". Dentre esses intelectuais destacaram-se os apelidados por Afrânio Peixoto, "cardeais da Escola Nova no Brasil", Anísio Teixeira, Fernando de Azevedo e Manoel Bergström Lourenço Filho, responsáveis pelas principais manifestações do escolanovismo no Brasil deixando, inclusive, sua própria interpretação da história da educação brasileira sob a ótica de suas realizações (MAGALDI; SCHUELER, 2009). Dos três, incontestavelmente, Lourenço Filho foi quem mais se identificou com o governo, especialmente se considerarmos sua atuação durante o Estado Novo, momento de exacerbação do nacionalismo, sempre acalentado por ele ainda que não da forma autoritária assumida durante o regime de exceção varguista ao qual, como veremos, ele teve de se submeter se quisesse ver suas propostas realizadas para a escola primária brasileira. Como mostrou Vieira (2015, p. 5), o intelectual vinculado ao campo educacional "segundo a representação e a autorrepresentação inúmeras vezes afirmadas, distingue-se daqueles que se manifestam nas questões públicas a partir das suas paixões ou de seus interesses econômicos ou políticos particulares", fazendo com que a apreciação de sua biografia traga subsídios relevantes para a interpretação do período histórico considerado neste artigo. 
UMA CARREIRA BRILHANTE

Discorrendo sobre os educadores profissionais no período em pauta, Miceli (1979, p.168-169) ressalta a influência do meio familiar na fortuna literária de Lourenço Filho:

A chance de escrever os resumos dos filmes a serem editados nos programas distribuídos no cinema local, e de colaborar no jornal da cidade, ambos de propriedade do pai, a leitura das obras que estavam a venda na loja, e outras experiências similares, decerto contribuíram para o entusiasmo com que Lourenço Filho se aferrou aos estudos a partir do momento em que se torna aluno de um jovem professor normalista, recém-formado em São Paulo.

Sem dúvida a atuação de seu pai como negociante de bens culturais na pequena cidade de Porto Ferreira iria marcar indelevelmente a trajetória de Lourenço Filho. De fato, quando tinha apenas oito anos ele já produzia o jornalzinho semanal O Pião do qual era "chefe, único redator e tipógrafo", espelhando-se diretamente na experiência paterna ${ }^{2}$. Envolvido desde a infância com os impressos que seu pai negociava no interior paulista, Lourenço Filho, por onde passou, deixou sua marca de produtor literário, desde a Revista de Educação em Piracicaba, passando pelos Arquivos do Instituto de Educação no Rio de Janeiro, até a miríade de publicações engendradas como diretor do Instituto Nacional de Estudos Pedagógicos (INEP). O empenho da família em sua escolarização será assinalado especialmente pelo exemplo do jovem normalista, que sucederia ao ensino rígido dado por um professor tradicional e que o levaria a seguir também a carreira de professor. Em suas aulas na Escola Normal de Piracicaba podemos perceber a influência dessa experiência: na ementa de educação moral e cívica por ele elaborada logo depois da "responsabilidade do professor primário" ele acrescenta "a lição do exemplo" reconhecendo implicitamente o papel do professor no acionamento da vocação docente (KULESZA, 2005, p. 306). Num trabalho posterior, apresentado originalmente na II Conferência Nacional de Educação realizada em Belo Horizonte em 1928, analisando criticamente a vocação para o magistério, ele aponta o papel do meio social na determinação da escolha por essa carreira, destacando a "influência direta muitas vezes dos nossos primeiros mestres que tomamos como modelo" (LOURENÇO FILHO, 2001a, p. 7). 
Formado pela Escola Normal Primária de Pirassununga, Lourenço Filho, depois de uma breve experiência como professor primário em sua cidade natal, desloca-se para São Paulo. $\mathrm{Na}$ Capital ele se vale de seus conhecimentos de tipografia para se aproximar dos jornais e editoras, passando logo a redator do Estado de São Paulo de Júlio de Mesquita Filho e da Revista do Brasil de Monteiro Lobato. Enquanto se prepara para seguir um curso superior, ele continua sua carreira na educação titulando-se pela Escola Normal Secundária habilitando-se assim a ser professor das escolas normais primárias. Instado por seus professores em 1917, ele adere à Liga Nacionalista de São Paulo passando a proferir conferências em prol da campanha pela obrigatoriedade do serviço militar promovida pela Liga ${ }^{3}$. Dessa maneira, Lourenço Filho enceta uma rápida e brilhante carreira consolidando sua posição de profissional da educação entre a operante intelectualidade de São Paulo na década de 1920. Logo, é nomeado para ser professor de cadeira de pedagogia e psicologia da Escola Normal de Piracicaba, cadeira profissionalizante do curso e assume também a docência da Prática Pedagógica realizada na escola modelo anexa.

Analisando o programa de 1921 em sua disciplina de Prática Pedagógica em Piracicaba, podemos apreciar sua inquietação com a questão da nacionalidade, exacerbada pela sua condição de membro atuante da Liga Nacionalista, incorporado em São Paulo. Assim, ele destaca na ementa da disciplina Metodologia da Linguagem Oral o "valor da língua como fator da unificação nacional", na de Metodologia da Geografia para a escola primária a "importância do ensino desta disciplina na formação do sentimento da nacionalidade"; por sua vez, na ementa de Metodologia da História consta o item "a história e o patriotismo" e na de Metodologia do Ensino Moral e Cívico ele arremata "o civismo não pode ser ensinado só por fórmulas, pelo culto abstrato de símbolos, mas, sim, basear-se no conhecimento do país, pela geografia, pela história e pelo idioma nacional" (LOURENÇO FILHO, 2001b, p. 67). Em 1922 ele parte para o Ceará convidado para ministrar as mesmas cadeiras pelas quais era responsável em Piracicaba na Escola Normal da Fortaleza e acaba assumindo a Diretoria Geral de Instrução Pública para realizar a famosa reforma do ensino naquele estado nordestino, iniciando assim sua também luminosa carreira de administrador da educação. Com podemos ver pelas 
monografias produzidas por suas alunas em Fortaleza (BASTOS; CAVALCANTE, 2009), Lourenço Filho reproduz em Fortaleza basicamente o mesmo programa de Piracicaba. Analisando a monografia referente à disciplina "metodologia do ensino moral e cívico", Bastos (2009, p.142) afirma que ela "expressa as ideias e organização metodológica que Lourenço Filho já expressara" no artigo sobre Prática Pedagógica, acima citado. O mesmo pode-se dizer da "metodologia do ensino da linguagem", dissertação escrita pela aluna Margarida Saboya e analisada por Razzini (2009, p.172), que também fez a comparação com o programa de Piracicaba:

À primeira vista, os tópicos introdutórios do texto de Margarida Saboya coincidem apenas com os tópicos de "metodologia da linguagem oral" do programa de "Prática Pedagógica". Entretanto, uma leitura atenta do texto da normalista mostra que, os temas destacados no item seguinte do programa de Lourenço Filho, sobre a "metodologia da linguagem escrita" também foram tratados por ela.

No caso do conteúdo de "metodologia do ensino de geografia", embora o programa tenha sofrido algumas alterações, não poderia faltar como em São Paulo, o item "a Geografia na Escola Primária e sua importância na formação do sentimento da nacionalidade" (FISCHER, 2009, p. 243). O desenvolvimento do assunto pela normalista permite perceber que o entendimento de Lourenço Filho sobre a importância da geografia não diferia de outros intelectuais dessa época, todos enaltecendo o patrimônio geográfico brasileiro, sem igual no restante do mundo, como ele explica:

O valor da Geographia na formação do espírito de nacionalidade é muito grande. Dando-nos o conhecimento de nosso país, de seus recursos naturais, de sua belleza, sua riqueza [...] faz-nos despertar o coração, vibrar a alma de enthusiasmo por esse Brasil immenso, que qual gigante adormecido, espera apenas por seus filhos [...] É, pois, como vimos, estudando a Geographia que pudemos com o máximo orgulho dizer "Sou brasileiro" (FISCHER, 2009, p. 244-245).

Finalmente, a monografia da normalista Aline Silva a respeito da "metodologia do ensino de história", analisada por Cunha e Stephanou (2009, p.267), também confirma a adaptação do programa de Piracicaba à escola cearense mantendo a orientação geral de "formação da nacionalidade". Para 
essas autoras Lourenço Filho opta, "de forma contundente", por uma História Pátria, "identificada como uma História de cunho nacionalista, afeita a seus próprios interesses" e que elas resumem assim:

Despertar na alma da criança, em seu processo formativo, o amor pela pátria, inconteste, que não poupe esforços para seu engrandecimento, que some suas energias ao progresso da nação Brasil. Cantar, comemorar, mirar-se nos exemplos, exercitar o civismo. Nos meandros, a afirmação da necessidade de uma homogeneidade cultural para a qual a escola poderia concorrer poderosamente: todos irmanados com o mesmo sentimento pátrio, identificados, segundo as práticas escolares, com os mesmos rituais, heróis, símbolos (CUNHA; STEPHANOU, 2009, p. 279).

A experiência de Lourenço Filho no Ceará durou apenas dois anos incompletos, mas traria consequências imediatas para sua carreira e suas concepções sobre o ensino primário e normal. Em primeiro lugar, ele conheceu de perto a realidade de uma região que começava a ser estigmatizada pelo flagelo da seca, constituindo o miserável e atrasado Nordeste, concepção para a qual Lourenço Filho iria contribuir consideravelmente através de seus artigos nos jornais paulistas, mais tarde enfeixados no livro "Joazeiro do Padre Cícero", premiado pela Academia Paulista de Letras. A questão nacional aflorava aí visivelmente e a "educação popular", como se dizia na época, era um dos seus componentes essenciais na época do "entusiasmo pela educação" abraçado pelos intelectuais no Brasil (NAGLE, 1974). Respondendo ao inquérito realizado pelo jornal O Estado de São Paulo em 1926, à pergunta sobre Qual o verdadeiro papel que deve caber à escola primária na formação do caráter nacional?, Lourenço Filho explicita claramente o sentido que atribuía à nacionalização do ensino primário, não a limitando à necessidade de assimilação do imigrante:

Mas no caso particular da sociedade brasileira, compete à escola, ainda um papel de vulto. Ela deve ser, precisa ser, a homogeneizadora da vida nacional [...] Por isso, entendo que a escola precisa ser fundamentalmente nacionalizadora, integrando não só o estrangeiro, mas o próprio sertanejo, tanto ou mais desviado, por certos aspectos, do que o imigrante, em relação à vida contemporânea política e social. 
Por outro lado, sua atuação na administração escolar em convivência íntima com o poder autocrático das oligarquias cearenses, não poderia deixar de instilar nele concepções autoritárias acerca da administração pública. Nelson Craveiro, inspetor escolar, descreveu bem em seu artigo "A evolução do ensino no Ceará e a reforma de 1922", publicado em 1923, o contexto no qual ocorria aquela a reforma do ensino:

Compreendeu logo o Sr. Justiniano de Serpa, presidente do Estado, que não tinha a seu lado apenas um técnico, mas o homem de que precisava para realizar seu grande sonho de estadista e de patriota. E apenas inteirado disso, isolou a instrução da influência dos políticos, entregando ao professor paulista, armado com poderes discricionários, toda a máquina administrativa do ensino (MONARCHA, 2010, p. 38, grifo do autor).

A experiência direta com a administração escolar iria daí por diante abrir para Lourenço Filho também essa possibilidade profissional, ofuscando pouco a pouco suas carreiras de professor e pesquisador. É nessa condição que Lourenço Filho vivencia no Ceará o aspecto econômico da questão nacional, mais precisamente o mercado de bens culturais em expansão como consequência direta e imediata do avanço da industrialização no país e que o remeteria novamente à experiência paterna. De fato, como mostrou Razzini (2009), Lourenço Filho atuou como uma espécie de intermediário entre as editoras paulistas e o governo cearense, contribuindo decisivamente para a comercialização nesse estado nordestino de livros e materiais didáticos produzidos em São Paulo, iniciando assim a face empresarial de sua diversificada atuação como redator, editor, autor, tradutor e organizador de livros e coleções. É a partir daí que ele passa a incorporar ao seu discurso o tema da "organização da cultura" como uma condição básica para a formação da nacionalidade, como pré-quesito mesmo para a organização da nação (CARVALHO, 1999).

Promovido em 1925 a professor da Cadeira de Psicologia e Pedagogia na Escola Normal de São Paulo, Lourenço Filho inicia também suas primeiras pesquisas junto ao Gabinete de Antropologia e Psicologia Experimental, vinculado àquela Cadeira. Todavia, seja em seus trabalhos experimentais de classificação dos alunos para efeito da racionalização de sua aprendiza- 
gem, seja na organização do currículo escolar para uma sociedade cada vez mais urbana e industrializada, pode-se identificar em Lourenço Filho sua preocupação constante com o objetivo de nacionalizar a população através da educação. Assim, nomeado delegado de São Paulo para a I Conferência Nacional da Educação, realizada em Curitiba em 1927, dentre as teses oficiais propostas ele escolhe justamente discorrer sobre "A uniformização do ensino primário nas suas ideias capitais, mantida a liberdade de programas" (COSTA, SCHMIDT; SHENA, 1997, p. 244 - 688). Reconhecendo que no Brasil "não há um meio social homogêneo, mas sociedades múltiplas, de variada organização e desenvolvimento, com exigências e possibilidades que lhe são peculiares" (LOURENÇO FILHO, 1997, p. 245), ele mostra que a desejada uniformização do ensino primário não pode significar uma padronização rígida das escolas. Daí que"o trabalho educativo deve procurar exatamente disfarçar e amenizar pela cultura cívica, tanto quanto possível, esses choques de interesses restritos, fazendo compreender e amar os da comunhão nacional" (LOURENÇO FILHO, 1997, p. 246), caso se queira atingir a uniformidade na formação das crianças.

Com a ascensão da Aliança Liberal ao poder em 1930, Lourenço Filho foi nomeado Diretor da Instrução Pública do Estado de São Paulo onde, no breve e conturbado espaço do primeiro ano da intervenção federal em São Paulo, promoveu uma reestruturação geral do sistema de ensino paulista. Meses antes ele havia lançado "Introdução ao estudo da Escola Nova", livro em grande parte responsável pela alcunha de "escolanovista" dada ao movimento reformador do ensino nos anos de 1930. Dividido entre a carreira de professor de pedagogia, pesquisador de psicologia educacional e administrador do ensino, pouco a pouco ele vai dando preferência à consolidação de sua posição como "técnico em educação" na burocracia estatal, prevalecendo-se de sua reputação como"pioneiro da educação nova". A consagração de seu trabalho como "profissional da educação" na burocracia estatal pode ser comprovada pela indicação unânime do seu nome para membro do Conselho Nacional de Educação em 1936 (MICELI, 1983, p. 409).

Como administrador escolar, participou efetivamente da reforma levada a cabo na capital da República por Anísio Teixeira, no cargo de diretor do Instituto de Educação de 1932 a 1937, sobrevivendo assim ao seu criador, 
substituído em 1935 na Diretoria de Instrução Pública do Distrito Federal por Francisco Campos. Todavia, sua ambição começaria a ser satisfeita quando foi nomeado em 1937 por Gustavo Capanema para o cargo de Diretor do Departamento Nacional de Educação, segundo cargo no escalão do ministério na área de educação ${ }^{4}$. Seu objetivo de implantar uma política nacional de educação para o ensino primário e normal transparece já no seu discurso de posse no novo cargo quando expressa seu desejo de romper com "a tradição que nos ficava do Ato Adicional de 1834 em que se esquecia a nação" (apud LOPES, 2006, p. 234), exaltando assim a esfera nacional de governo frente à estadual ou municipal no campo educacional. Valorizando nesse seu discurso sua condição intelectual de "profissional da educação", Lourenço Filho enuncia claramente a sua estratégia de utilizar seus conhecimentos de normalista para tentar impor seus pontos de vista educacionais no âmbito do Ministério.

\section{A NACIONALIZAÇÃO DO ENSINO EM MARCHA}

Com o endurecimento do regime de Vargas a partir de novembro de 1937, a questão nacional ressurge com toda força estimulada pela eminente eclosão da Segunda Guerra. É nesse contexto que, no ano seguinte, finalmente, Capanema consegue acomodar seu valioso auxiliar numa função nacional apropriada, não só nominalmente, mas por ser um instrumento fundamental para o estabelecimento de uma política educacional de educação, então esvaziada pelas dificuldades de operacionalizar o Plano Nacional de Educação previsto na constituição de 1934. Nomeado diretor do INEP em 1938, Lourenço Filho assume também a responsabilidade por sua organização, permanecendo no cargo até o fim do Estado Novo varguista em 1945 e onde ele pôde colocar em prática suas ideias de nacionalização do ensino primário em oposição ao federalismo reinante, favorecido pela centralização do poder do governo autoritário. O depoimento insuspeito de Alceu Amoroso Lima na edição comemorativa da Associação Brasileira de Educação homenageando Lourenço Filho em 1959, "um espírito sereno, equilibrado, objetivo, conciliador, curioso de todas as inovações filosóficas sem se filiar a qualquer delas, de um liberalismo bastante seduzido pela autoridade" (apud LOPES, 2006, p. 
245), ilustra bem como ele estava à vontade na ditadura getulista: o traslado da Escola Nova para o Estado Novo seria para Lourenço Filho meramente uma generalização, uma extensão institucional.

Aproveitando seu conhecimento acumulado a respeito do ensino primário e normal e prevalecendo-se do desinteresse do Ministério conduzido por Capanema nesses níveis de ensino, Lourenço Filho procurou desde logo ocupar esse espaço começando a fazer um levantamento da situação nos diversos estados da federação ${ }^{5}$. Cauteloso, ele começou pelos estados geograficamente mais afastados e com pouca expressão política, começando pelo Amazonas, Pará, Maranhão, Piauí, Ceará, Rio Grande do Norte, para em seguida descer em direção ao sul do país. Esses estudos deram origem a uma série de boletins publicada pelo INEP a partir de 1939, intitulada "Organização do Ensino Primário e Normal", encerrada em 1945 com a publicação do número referente ao Rio Grande do Sul. Antes da publicação desses levantamentos, feitos normalmente à distância através do envio de questionários e que poderiam trazer revelações inconvenientes sobre a situação educacional do estado para os políticos locais, Lourenço Filho tinha o cuidado de submeter o seu conteúdo ao visto da maior autoridade educacional do estado em pauta, tornando-o assim corresponsável pela publicação da pesquisa.

Às vésperas da eclosão da Segunda Guerra Mundial, tornava-se cada vez mais candente a questão da nacionalização do ensino em todos os níveis, ensejando assim ações imperativas por parte do governo, logo assumidas pelo INEP. Como mostrou Rocha (1990, p.85), a criação da Comissão Nacional de Ensino Primário (que contava com Lourenço Filho como diretor do INEP) em novembro de 1938, atendia às "razões imediatas da desnacionalização do ensino primário, nas áreas de colonização estrangeira". Afinal, essa questão desafiava diretamente o programa nacionalizador do Estado Novo, agravado pela iminente irrupção do conflito envolvendo Alemanha e Itália, países de onde provinha grande quantidade dos colonos estabelecidos no sul do país. Ou seja, se no conjunto do país a rígida permanência de uma prática política localista obstaculizava a implantação de uma política nacional de educação, a presença de núcleos estrangeiros nas zonas de colonização dificultava ainda mais esse desiderato (BOMENY, 1999, p. 151). Dessa maneira, estaria justifica- 
da a intervenção de Lourenço Filho, através do INEP, no sistema educacional não mais apenas de estados politicamente insignificantes, mas também nos importantes estados do sul e sudeste do país, onde se localizava a grande maioria dos imigrantes estrangeiros que haviam se fixado no país.

O caráter técnico, politicamente "neutro" do INEP, só poderia ser acionado se o órgão fosse explicitamente convocado para contribuir com a organização da educação num determinado estado. Essa oportunidade de intervenção direta seria dada a Lourenço Filho, quando foi convidado, juntamente com Everardo Backheuser, para um "curso de aperfeiçoamento pedagógico" destinado aos professores estaduais do Rio Grande do Sul. Convidados pelo secretário da educação, José Pereira Coelho de Souza, os "técnicos do INEP" cumpriram um extenso programa na capital gaúcha que se estendeu de 14 a 26 de junho de 1939. Num total de 16 horas de aula, oito para cada conferencista, Lourenço Filho, demonstrando sua dupla competência, discorreu sobre "psicologia da aprendizagem"e "problemas de administração escolar", enquanto Everardo Backheuser falou sobre "diretrizes da nova didática e ensino globalizado: método de projetos" (QUADROS, 2006, p. 93). Fora das duas horas diárias destinadas às aulas, os visitantes cumpriram uma vasta programação de visitas a instituições de ensino gaúchas durante o restante do tempo. Foi nessa ocasião que Coelho de Souza solicitou a Lourenço Filho um anteprojeto de organização da Secretaria de Educação, trabalho extensamente citado por ele na exposição de motivos que deu origem ao decreto no 578 de 1942, que efetivamente reorganizou a Secretaria da Educação do principal estado sulino.

Analisando a premência da nacionalização do ensino nas transformações da educação gaúcha nesse período, Quadros $(2006$, p. 213) destaca que

o reaparelhamento da Secretaria de Educação e Saúde Pública, com a ampliação de sua estrutura administrativa e a implantação de novas formas de gestão educacional, no âmbito das quais adquiriram proeminência uma extensa e minuciosa normatização e burocratização além de uma forte vontade disciplinante que se manifestou na prescrição detalhada dos programas de ensino e das atividades escolares, na orientação pedagógica ao magistério e no controle rigoroso e detalhado da execução da reforma educacional. 
Em sua pesquisa, Quadros constata que Lourenço Filho foi uma fonte de inspiração e estímulo que, segundo o testemunho de Coelho de Souza, "se refletiu na nossa vida escolar por muitos anos e contribuiu para elevar o nível do ensino primário e normal no Rio Grande" (2006, p. 116). Não há dúvida que na base dessas modificações estava a proposta de nacionalização do ensino que, como vimos, permeava toda a ação de Lourenço Filho nesse período, mesmo que fosse com prejuízo de seus princípios escolanovistas. De fato, em seu estudo sobre um dos principais instrumentos de implantação da reforma educacional no Rio Grande do Sul nesse período, a Revista do Ensino, Bastos (2005, p. 237), conclui que a proposta da "escola estadonovista" gaúcha

subordinava à dimensão cívico-nacionalizadora as invocações pedagógicas identificadas com o ideário escolanovista. A escola era redimensionada incorporando ambientes, novo mobiliário, novos materiais e símbolos - pátrios e religiosos - através de diferentes estratégias - auditórios, projetos, centro de interesse, excursões. Toda ação procurava destacar a finalidade cívico-social que assumia a escola como instrumento de moralização e regeneração social no âmbito da política educacional estadonovista.

Mas Lourenço Filho não limitou sua ação aos professores e gestores do ensino. Na condição de diretor do INEP ele se tornou um ativo publicista da nova ordem, sendo convidado para pronunciar conferências em várias instâncias governamentais. Assim, em 1940, convidado pelo poderoso órgão censor do governo, o Departamento de Imprensa e Propaganda, ele discorre sobre as "Tendências da Educação Brasileira", fazendo um extenso apanhado da história da educação no país "condenando as velhas tendências" e detendo-se com vagar nos anos pós-30 quando "novas diretrizes tomam corpo". Revelando estar em sintonia com o momento político, afirma que "A Nação toma consciência de si mesma e realiza um esforço de coesão. Compreende-se que a educação tenha de ser posta, antes de tudo, na direção de objetivos nacionais de ordem, de segurança, de disciplina". Encerrando sua fala, ele cita "claras, incisivas e profundas palavras", retiradas de um discurso de Getúlio Vargas, proferido no ano anterior onde o ditador mostra a dependência programática dos objetivos educacionais das necessidades da nação (LOURENÇO FILHO, 2002, p. 31). 
Alguns meses depois, convidado pela Escola de Estado-Maior do Exército, Lourenço Filho, discorrendo sobre "Educação e Segurança Nacional", volta a destacar a importância do ensino primário para a nacionalidade:

A educação primária deve ter como fito capital “homogeneizar" a população, dando a cada nova geração o instrumento do idioma, os rudimentos da geografia e da história pátria, os elementos da arte popular e do folclore, as bases da formação cívica e moral, a feição dos sentimentos e ideais coletivos, em que, afinal, o senso da unidade e o da comunhão nacional repousam" (LOURENÇO FILHO, 2002, p. 68).

E, para calar os defensores de um militarismo que ansiava deixar boa parte desses objetivos educacionais sob a responsabilidade dos militares, Lourenço Filho defende a complementaridade da ação desses dois agentes sociais: "Pode-se dizer que as forças armadas e a corporação dos educadores, trabalhem seus membros no extremo sul ou sob as florestas da Amazônia, hão de compor as falanges de um só e mesmo exército" (LOURENÇO FILHO, 2002, p. 70).

Mas é na Academia Brasileira de Letras que Lourenço Filho, convidado pela Liga de Defesa Nacional, põe-se à vontade para falar dentre todas as modalidades de ensino "daquela que ao maior número atinja; da que mais extensamente comunique; daquela que possa reforçar a trama de ideias e de sentimentos, por força da qual o espírito mesmo da Nação se organiza", ou seja, o ensino primário, cujo "papel primeiro é, sem dúvida alguma, o de formar no homem a consciência da Nação" (LOURENÇO FILHO, 2002, p. 35-37), desfraldando desta maneira, com todo vigor, sua bandeira de luta pela nacionalização da escola primária no Brasil. Já de posse da maioria dos levantamentos que o INEP fazia para a publicação da série sobre o ensino primário e normal, Lourenço Filho mostra como na legislação encontrada, por causa do federalismo até então reinante, "não se acentua a função de integração nacional que deve ter a educação primária", menosprezando assim sua "função nacionalizadora" (LOURENÇO FILHO, 2002, p. 44). Dada a vinculação orgânica entre o ensino primário e o ensino normal, Lourenço Filho estenderia essa função nacionalizadora para as escolas normais, como se pode ver na proposta que elaborou e foi apresentar pessoalmente na Paraíba em 1942 sobre a organização do ensino nesse estado (LOURENÇO FILHO, 1942). 
Frisando a virada havida com o Estado Novo, Lourenço Filho afirma à intelectualidade presente na Academia:

se a Revolução de 30 experimentou reforçar os laços da nacionalidade, não será demais dizer que só depois da criação do Estado Nacional, em 1937, é que esses laços, na verdade, agora se consolidam. A Constituição de 1934 já consagrava o princípio da existência de "diretrizes nacionais da educação". A de 1937 reafirmou-o. E o Decreto n 868 , de novembro de 1938, criando uma Comissão Nacional de Ensino Primário para o estudo das questões básicas de sua organização, orientação e articulação em todo o país, veio definir uma política que, sem demora, deve ser executada (LOURENÇO FILHO, 1942, p.44, grifo do autor).

Valendo-se de uma frase de José Veríssimo segundo a qual "uma reforma profunda na educação pública e nacional presume uma reforma igualmente radical no governo", ele conclui sua conferência com uma exortação que o identificava nitidamente com o regime:"nós tivemos a reforma radical no governo, cumpre-nos agora completar a obra da revolução pela reforma profunda da educação nacional" (LOURENÇO FILHO, 1942, p. 55). Assim, ao contrário da avaliação de Lopes (2006, p. 248), ao constatar o silêncio em suas conferências sobre as realizações educacionais no Distrito Federal sob a liderança de Anísio Teixeira, "tornava-se, de fato, difícil para Lourenço Filho combinar as concepções que serviam de base às diretrizes do novo momento histórico com os ideais pedagógicos remanescentes do movimento da Escola Nova", nos parece que os seus próprios ideais pedagógicos, especialmente sua inabalável convicção sobre o papel nacionalizador da escola, estavam em perfeita conformidade com o novo regime e, inclusive, sobreviveriam por um longo tempo na educação brasileira mesmo após a "redemocratização" do país a partir de 1946.

\section{ConCLUSÃo}

Constatando também que nessas conferências enfeixadas por Lourenço Filho em 1940 no livro Tendências da educação brasileira, "não há referências diretas ou indiretas ao movimento da Escola Nova", Monarcha (2002, p. 9) faz o seguinte comentário: 
Essa ausência talvez possa ser explicada pelo fato de que a inquietação da Escola Nova, decorrente tanto de um cosmopolitismo desenraizado e universalista quanto do ideal de reconstrução da experiência, não fosse a mais adequada ao estado de coisas reinante, em cujo interior propagava-se a solidariedade social orgânica, tão característica das vogas de autoafirmação nacionalistas.

Ou seja, que Lourenço Filho agia de maneira pragmática procurando evitar os obstáculos num campo permeado de conflitos mesmo entre a chamada "trindade cardinalícia" do movimento escolanovista constituída por ele, Fernando de Azevedo e Anísio Teixeira. Assim, por exemplo, em 1931, Fernando de Azevedo criticou a rápida implantação em São Paulo do decreto de iniciativa de Francisco Campos que permitia o ensino religioso nas escolas públicas em 1931, quando ele era diretor de instrução em São Paulo e, logo depois, pode-se ver na correspondência de Azevedo sua mágoa pela aceitação por Lourenço Filho da chefia de gabinete de Francisco Campos. Nesse caso, Azevedo ressalva que embora não tenha sido ele quem pleiteara "esta função meramente política", Lourenço Filho não a deveria ter aceitado, "deixando, entregues à sua sorte, na campanha que ele aqui, conosco, abriu e sustentou com nosso apoio constante pela renovação educacional". Na mesma carta, Azevedo manifesta sua estranheza com essa aceitação, pois, Lourenço Filho "sempre se manifestou inteiramente contrário às reformas do Ministro Francisco Campos, que, para ele, era um ministro que sacrificara os interesses da educação aos interesses domésticos de sua política, em Minas" (apud MACEDO, 2013, p. 63). Todavia, na mesma época da recondução do mineiro Francisco Campos ao Ministério da Educação e Saúde, no início de dezembro de 1931, Lourenço Filho, já destituído da diretoria de instrução de São Paulo e estando em Belo Horizonte para paraninfar uma turma de concluintes do Colégio Izabela Hendrix, concedeu uma entrevista ao jornal Estado de Minas elogiando a reforma Francisco Campos, especialmente a Escola de Aperfeiçoamento, afirmando que "isto que só agora São Paulo experimenta, já há bons dois anos Minas vem tentando, com o resultado que todos conhecem". Como ele tinha acabado de deixar a direção da educação em São Paulo, o repórter então pergunta incisivamente: "Quer dizer que o ensino de Minas apresenta superioridade sobre o de São Paulo?" e Lourenço 
Filho responde: "Por certos aspectos, é essa a minha conviç̧ão"6. Dias depois ele estará no Rio de Janeiro, onde exercerá doravante toda sua carreira, para assumir a chefia de gabinete do ministro que havia realizado a reforma da educação mineira.

Inspirado nas análises de Durkheim sobre a função homogeneizadora do ensino primário e sobre o papel da escola de massas na constituição dos estados nacionais europeus, Lourenço Filho responde ao diagnóstico generalizado da intelectualidade de seu tempo que considerava o Brasil um país inconcluso, uma nação deficiente com um povo atrasado, invertendo o argumento: é justamente através da nacionalização da escola que se constituirá um estado nacional homogêneo e sustentável'. Entretanto, a homogeneização propugnada por ele é muito mais geográfica do que social, pretendendo subsumir os regionalismos, "abrasileirar o brasileiro" (apud LOURENÇO, 1997, p. 56), para assim constituir uma "alma nacional compartilhada por todos independentemente de sua posição social. Por isso, ele não podia concordar com alguns de seus colegas da Liga de Defesa Nacional, como Olavo Bilac, que identificavam a "alma nacional" com a pátria, entidade claramente associada à ordem e à disciplina, mantendo o credo liberal que, para ele, decorria naturalmente de seus estudos de psicologia. Todavia, o seu raciocínio não podia prescindir da identificação entre nação e estado, premissa básica dos regimes totalitários europeus da primeira metade do século passado, daí a sua preterição do escolanovismo em favor do estadonovismo.

Artigo recebido em: 09/12/2015

Aprovado para publicação em: 01/02/2016

LOURENÇO FILHO AND THE NATIONALIZATION OF PRIMARY EDUCATION (19171945)

Abstract: Born in 1897 in a little town in the state of São Paulo, Manoel Bergström Lourenço Filho shared with Brazilians of his age all the tensions, anxieties and joys of being the son of a nation in search of its identity in the early twentieth century. This paper seeks to rebuild his career pointing out in the most significant moments the relationship between his concepts of nation, state and education and the proposals 
effectively assumed under the Brazilian Ministry of Education and Health. This analysis allows clearly perceive the use that Lourenço Filho makes of his expertise to try to impose his educational concepts in the definition of the policy for the primary and normal education during the period under consideration.

KEYWORDS: Intellectuals. New school. Educational policy. Primary education.

\section{LOURENÇO FILHO Y LA NACIONALIZACIÓN DE LA EDUCACIÓN PRIMARIA (1917 $-1945)$}

Resumen: Nacido en 1897 en un pequeño pueblo del interior del estado de São Paulo, Manoel Bergström Lourenço Filho compartió con los brasileños de su generación las tensiones, angustias y alegrías del ser hijo de una nación en busca de su identidad a principios del siglo XX. Este trabajo busca reconstruir su trayectoria profesional, señalando la relación entre sus conceptos de nación, estado y educación y las propuestas asumidas efectivamente por el Ministerio de Educación y Salud brasileño en sus momentos más significativos. Este análisis permite percibir claramente el uso que el intelectual Lourenço Filho hace de su experiencia profesional para tratar de imponer sus conceptos educativos en la definición de las políticas para la educación primaria y normal durante el período en consideración.

PalABRAS CLAVE: Intelectuales. Nueva escuela. Política educativa. Educación primaria.

\section{NOTAS}

1) Meta que seria alcançada apenas no final do século $X X$ e somente para o ensino fundamental.

2) Uma excelente biografia recente de Lourenço Filho pode ser encontrada em Monarcha (2010).

3) Todavia, como mostram Cunha e Stephanou (2009, p.261), analisando a orientação dele para o ensino de história na escola primária, a preocupação de Lourenço Filho com o nacional, em estreita associação com o patriotismo é anterior ao seu ingresso na Liga e citam um artigo publicado por ele em 1916, no qual ele considera que a língua portuguesa deveria ser o elo da nacionalidade constituinte de um "patriotismo são", dizendo que essa proposição "atravessa quase intemporalmente o pensamento de seu autor a partir da década de 1920".

4) Seu cargo no Ministério, equivalente ao de diretor do Departamento Nacional de Saúde, interferia na própria ação política do Ministro, fielmente defendida por seu 
chefe de gabinete, Carlos Drummond de Andrade, o que levou à sua exoneração decorridos apenas três meses no cargo apesar da pressão dos educadores e do próprio ministro para que permanecesse no posto (LOPES, 2006, p.235).

5) Como argumenta Bomeny (1999, p.139), durante a gestão de Capanema "o ensino primário sequer foi tocado. $\mathrm{O}$ ministro estava convencido de que com verdadeiras elites se resolveria não somente o problema do ensino primário, mas o da mobilização de elementos capazes de movimentar, desenvolver, dirigir e aperfeiçoar todo o mecanismo de nossa civilização".

6) Estado de Minas, 11/12/1931, primeira página.

7) Mesmo após o fim do Estado Novo, Lourenço Filho manteve seu credo sobre o papel fundamental da escola na formação da nação como se pode depreender deste trecho de uma conferência feita por ele na Associação Brasileira de Educação em 1952: “Na educação primária põe o regime a base mesma de sua existência. É como se dissesse: sem educação primária generalizada, universal, gratuita e obrigatória, não há cidadania. Sem cidadania não pode haver vida nacional no sistema representativo. Logo, sem educação primária, não há nação" (apud LOURENÇO, 1997, p.67).

\section{REFERÊNCIAS}

BASTOS, M. H. C. A Revista do Ensino do Rio Grande do Sul (1939-1942): o novo e o nacional em revista. Pelotas: Seiva, 2005.

. "Beber Luzes" Para Enaltecer o Espírito: o ensino moral e cívico. In: BASTOS, M.H.C.; CAVALCANTE, M. J. M. (Org.). O curso de Lourenço Filho na Escola Normal do Ceará. Campinas/SP: Alínea, 2009, p.129-148.

; CAVALCANTE, M. J. M.(Org.). O curso de Lourenço Filho na Escola Normal do Ceará. Campinas/SP: Alínea, 2009.

BOMENY, H. M. B. Três decretos e um ministério: a propósito da educação no Estado Novo. In: PANDOLFI, D. (Org.). Repensando o Estado Novo. Rio de Janeiro: Ed. da FGV, 1999, p.137-166.

CARVALHO, M. M. C. O território do consenso e a demarcação do perigo: política e memória do debate educacional dos anos 30. In: FREITAS, M. C.(Org.). Memória Intelectual da Educação Brasileira. Bragança Paulista: EDUSF, 1999, p.17-32.

COSTA, M. J. F. F.; SCHMIDT, M. A; SHENA, D. R. (Org.). I Conferência Nacional de Educação. Brasília: INEP, 1997.

CUNHA, M. T. S.; STEPHANOU, M. Despertar na alma da criança o amor pela pátria. In: BASTOS, M. H. C.; CAVALCANTE, M. J. M. (Org.). O curso de Lourenço Filho na Escola Normal do Ceará. Campinas/SP: Alínea, 2009, p.261-284. 
FISCHER, B.D. É, pois, estudando a geographia que pudemos com o máximo orgulho dizer "sou brasileiro". In: BASTOS, M. H. C.; CAVALCANTE, M. J. M. (Org.). O curso de Lourenço Filho na Escola Normal do Ceará. Campinas/SP: Alínea, 2009, p.241-260.

KULESZA, W. A. A Lição do Exemplo. In: CORRÊA, R. L. T.; MIGUEL, M. E. B. (Org.). A Educação Escolar em Perspectiva Histórica. Campinas/SP: Autores Associados, 2005, p.293-308.

LOPES, S. de C. Oficina de Mestres. Rio de Janeiro: DP\&A; FAPERJ, 2006.

LOURENÇO, L. M. S. O pensamento de Lourenço Filho em seus primeiros escritos pedagógicos e nas conferências da Associação Brasileira de Educação - ABE. In: MONARCHA, C. (Org.). Centenário de Lourenço Filho: 1897-1997. Londrina: UEL; Marília, UNESP; Rio de Janeiro, ABE, 1997, p.47-76.

LOURENÇO FILHO, M. B. A administração dos serviços de educação na Paraíba. Rio de Janeiro: Arquivo Lourenço Filho do Centro de Pesquisa e Documentação em História Contemporânea do Brasil da Fundação Getúlio Vargas (CPDOC), 1942.

. A uniformização do ensino primário no Brasil. In: COSTA, M. J. F. F.; SCHMIDT, M. A.; SHENA, D. R. (Org.). I Conferência Nacional de Educação. Brasília, INEP, 1997, p.244-249.

Há uma vocação para o magistério? In: LOURENÇO FILHO, R. (Org.). A formação de professores: da Escola Normal à Escola de Educação. Brasília: INEP, 2001a, p.7-18.

Prática pedagógica (programa de ensino). In: LOURENÇO FILHO, R. (Org.). A formação de professores: da Escola Normal à Escola de Educação. Brasília: INEP, 2001b, p.61-72.

. Tendências da Educação Brasileira. Brasília: INEP, 2002.

MACEDO, R.B.R. O Instituto de Pesquisas Educacionais do Distrito Federal nos anos de 1930. Tese (Doutorado em Educação) - Departamento de Educação da PUC, Rio de Janeiro, 2013.

MAGALDI, A. M. B. M; SCHUELER, A. F. M. Educação Escolar na Primeira República: memória, história e perspectivas de pesquisa. Tempo, v. 13, n. 26, p. 32-55, 2009.

MICELI, S. Intelectuais e Classe Dirigente no Brasil. São Paulo: DIFEL, 1979.

. O Conselho Nacional de Educação: esboço de análise de um aparelho do Estado (1931-1937). A revolução de 30: Seminário Internacional. Brasília: Editora Universidade de Brasília, 1983, p. 399-436.

MONARCHA, C. Prefácio. In: LOURENÇO FILHO, M.B. Tendências da Educação Brasileira. Brasília: INEP, 2002, p.7-10.

. Lourenço Filho. Recife: Editora Massangana, 2010. 
NAGLE, J. Educação e Sociedade na Primeira República. São Paulo: EPU; Rio de Janeiro: FENAME, 1974.

QUADROS, C. Reforma, ciência e profissionalização da educação: o Centro de Pesquisas e Orientação Educacionais do Rio Grande do Sul. Tese (Doutorado em Educação) - Faculdade de Educação da UFRGS, Porto Alegre, 2006.

RAZZINI, M. P. G. "Falar Bem a Própria Língua não é uma Prenda é um Dever": o cultivo da linguagem no curso de prática pedagógica de Lourenço Filho no Ceará. In: BASTOS, M. H. C.; CAVALCANTE, M. J. M. (Org.). O curso de Lourenço Filho na Escola Normal do Ceará. Campinas/SP: Alínea, 2009, p.149-194.

ROCHA, M. B. M. R. Educação conformada: a política pública de educação (19301945). Dissertação (Mestrado em Ciência Política) - Universidade Estadual de Campinas, Campinas, 1990.

VIEIRA, C. E. Intelectuais e Educação. Pensar a Educação em Revista, Curitiba/Belo Horizonte, v. 1, n. 1, p. 3-21, 2015.

WoJCIECH ANDRZEJ KulESZA: Doutor em Educação pela Universidade Estadual de Campinas (Unicamp). Atualmente é professor titular do Centro de Educação da Universidade Federal da Paraíba. Tem experiência na área de Educação, com ênfase em Fundamentos da Educação, atuando principalmente nos seguintes temas: instituições escolares, formação de professores, ensino de ciências, história da educação brasileira e história da educação.

E-mail:wakulesza@gmail.com 
